\section{Kidney Blood Pressure Research}

Kidney Blood Press Res 2018;43:1554-1562

DOI: 10.1159/000494441

Published online: 22 October 2018

Accepted: 12 October 2018

This article is licensed under the Creative Commons Attribution-NonCommercial-NoDerivatives 4.0 InternaThis article is licensed under the Creative Commons Attribution-NonCommercial-NoDerivatives 4.0 interna-
tional License (CC BY-NC-ND) (http://www.karger.com/Services/OpenAccessLicense). Usage and distribution tional License (CC BY-NC-ND) (http://www.karger.com/Services/OpenAccessLicense). Usage and dist
for commercial purposes as well as any distribution of modified material requires written permission.

\title{
Association Between Risk Factors Including Bone-Derived Biomarkers and Aortic Arch Calcification in Maintenance Hemodialysis Patients
}

\author{
Kosaku Nitta ${ }^{a}$ Norio Hanafusa ${ }^{b}$ Masayuki Okazakic Mizuki Komatsuc \\ Hiroshi Kawaguchic Ken Tsuchiyab \\ ${ }^{a}$ Department of Medicine, Kidney Center, Tokyo Women's Medical University, Tokyo, bepartment \\ of Blood Purification, Kidney Center, Tokyo Women's Medical University, Tokyo, 'Department of \\ Nephrology, Jyoban Hospital, Fukushima, Japan
}

\section{Key Words}

Vascular calcification • Sclerostin • FGF-23 • Hemodialysis

\begin{abstract}
Background/Aims: Aortic arch calcification (AoAC) is frequently detected in maintenance hemodialysis (MHD) patients and is associated with cardiovascular and all-cause mortality. We investigated the factors associated with AoAC and analyzed the relationship between the factors including bone-derived biomarkers and AoAC. Methods: We enrolled 389 stable MHD patients. AoAC was assessed using chest- $X$ ray examination. Demographic data was collected in addition to serum levels of biochemical and bone-derived biomarkers, including sclerostin and fibroblast growth factor-23 (FGF-23). Results: Two hundred sixteen patients (55.5\%) had AoAC. Patients with AoAC score $\geq 4$ were older, with a higher percentage being male, and exhibited lower serum levels of albumin and triglyceride. Serum FGF-23 levels were inversely associated with AoAC severity, and FGF-23was directly related to vascular calcification. Age, gender, and dialysis vintage were independent predictors of AoAC. Conclusion: MHD patients have a high prevalence of AoAC. The grade of AoAC was dependent on older age in association with longer dialysis vintage. Levels of circulating FGF-23 but not sclerostin were related to AoAC severity. Serum FGF-23 levels were independently associated with AoAC.
\end{abstract}




\section{Kidney Blood Pressure Research}

\section{Introduction}

Cardiovascular disease is the major cause of death in patients undergoing maintenance hemodialysis (MHD) [1]. One of the major factors contributing to the markedly increased cardiovascular mortality and morbidity is vascular calcification in patients with end-stage renal disease (ESRD) [2]. Recently, vascular calcification in the coronary arteries and the aorta has been recognized as an important risk factor for cardiovascular disease in MHD patients [3]. Although vascular calcification is considered an aging process in nature, the presence of calcification in any arterial wall is associated with a three-to-four-fold higher risk of cardiovascular events and mortality [4].

Noordzij et al. have demonstrated the association between the presence and extent of vascular calcification and outcome in the dialysis population [5]. The extent of vascular calcification can be quantified with electron beam computer tomography [6] and multidetector computer tomography [7]. Plain radiography is a convenient and inexpensive tool for the identification of vascular calcification. In the general population, aortic arch calcification (AoAC) identified in chest radiography has been shown to correlate with cardiovascular mortality in longitudinal follow-up periods [8].

We have recently reported the validity and usefulness of assessment of AoAC grade, as determined by a simple chest X-ray $[9,10]$. AoAC grade was significantly associated with a clustering of traditional risk factors. However, it is still unknown whether AoAC grade is a sensitive predictor of cardiovascular and all-cause mortality.

Sclerostin is synthetized by the osteocytes, and inhibits the bone anabolic Wnt pathway, which promotes bone formation [11]. It has already been shown that serum levels of sclerostin are elevated in hemodialysis patients, with an inverse correlation to serum parathyroid hormone (PTH) and bone formation rate [12]. In addition, Sabbagh et al. have recently detailed how an increased bone expression of sclerostin experimental models [13], and probably plays a role in the pathophysiology of renal osteodystrophy, potentially increasing bone resistance to PTH. As a consequence, it would be expected that higher sclerostin is associated with worse outcomes. Surprisingly, it has recently been shown in HD patients that high circulating sclerostin levels are associated with improved survival instead [14]. Therefore, there is still some debate on whether circulating sclerostin could be a new biomarker of outcome. In addition, the potential relationship of serum sclerostin with another biomarkers, for example, fibroblast growth factor-23 (FGF-23) or recently described sclerostin modulators, such as inflammatory cytokines [15], have not yet been evaluated.

To investigate these points, we conducted a cross-sectional study to analyze the factors that are associated with AoAC in MHD patients. We also measured circulating levels of bonederived biomarkers and determined their relationship with AoAC.

\section{Materials and Methods}

\section{Study population}

There were 402 stable MHD patients (dialysis duration > 6 months) at Jyoban Hospital Kidney Center, Fukushima, Japan, during July 2012; this constituted the study population. Of these, patients with acute illness, significant infection, or malignancy were excluded. Of the remaining patients, 389 patients (male/ female $=254 / 135$, mean age $66.1 \pm 12.9$ years) provided their informed consent for evaluating a chest radiograph, as described next, and were thus investigated in the present study. The underlying causes of ESRD were diabetes $(n=178)$, chronic glomerulonephritis $(n=128)$, hypertensive nephropathy $(n=73)$, polycystic kidney $(n=6)$, and unknown etiology $(n=4)$. The enrolled patients underwent stable regular HD using bicarbonate dialysate. At baseline, a chest radiograph of each patient was obtained. They comprised a random sample of patients from the Kidney Center in Jyoban Hospital without a selection bias. This study was in compliance with the Declaration of Helsinki and was approved by the ethics review committee (No. 26-1) of Jyoban Hospital. 


\section{Kidney Blood Pressure Research}

\section{Assessment of AoAC}

We performed a retrospective review of 389 patients undergoing dialysis therapy. Two radiologists (one specializing in chest radiography) independently reviewed all chest radiographs obtained from MHD patients studied. Radiographs were assessed for the presence of AoAC using a specific scale as previously described by Ogawa et al. [9]. The scale which was divided into sixteen circumferences was attached to the aortic arch on chest X-ray and then the number of sectors with calcification was divided by 16 . Aortic arch calcification score (AoACS) was calculated after multiplication by 100 to express the results as a percentage. This value was used as the indicator of the AoAC. Our previous study confirmed that AoACS was highly correlated with AoAC volume evaluated by MSCT ( $\mathrm{r}=0.635, \mathrm{p}<0.001)$ [9]. The extent of AoAC was divided into four grades according to the following categorization. Group I, AoACS=0\%; Group II, AoACS=1-3\%; Group II, AoACS=4-12\%.

\section{Laboratory and hemodynamic measurements}

Blood was drawn prior to initiating a dialysis session in a fasting state. Serum albumin, calcium, phosphate, total cholesterol, high-density lipoprotein (HDL) cholesterol, triglyceride, blood sugar, C-reactive protein (CRP) and the concentration of hemoglobin were measured by using routine laboratory methods. The mean values of three measurements during the 3 months before chest radiography were used for analysis. Serum intact parathyroid hormone (PTH) was measured once at the time of radiography. Serum calcium levels were adjusted using the formula [calcium + (4-albumin)]. On the same day, blood samples were collected and frozen, while serum samples were stored for further analyses. Serum FGF-23 level was measured by sandwich-type enzyme-linked immunosorbent assay (ELISA) for human human FGF-23 (Kainos Laboratories Inc., Tokyo, Japan), which measures biological active, full-length FGF-23 using two monoclonal antibodies for FGF-23, as described previously [16, 17]. The intra-assay coefficient of variation of the measurement was $<10 \%$. Serum sclerostin level were measured by sandwich-type ELISA using commercial reagents (Biomedica Medizinprodukte, Vienna, Austria, as described previously [18]. The intraassay coefficient of variation of the measurement ranged from 5 - 7\%.

The clinical status of all subjects was evaluated by means of routine clinical examination before the regular HD session. Systolic and diastolic blood pressures (BPs) were measured with a mercury sphygmomanometer with the patient in the supine position after 10 to 15 minutes of rest, and the mean values for one month were used for the analysis. Hypertension was defined as: (a) predialysis systolic blood pressure greater than $140 \mathrm{mmHg}$, (b) diastolic blood pressure greater than $90 \mathrm{mmHg}$, or (c) if they were using any antihypertensive therapy.

\section{Statistical analysis}

Continuous variables were expressed as means \pm SD and categorical variables as percentages. Spearman's correlation analysis, a nonparametric test, was used to assess the relationship among bonederived biomarkers, clinical and biochemical factors, and AoACS. All subjects were subsequently stratified into four groups, depending on the AoACS. In order to compare the different AoAC severity groups, the chi-square test was used for categorical variables and either the one-way analysis of variance (ANOVA) or the Kruskal Wallis test was utilized for the continuous variables featuring normal or skewed distribution, respectively. The levels of bone-derived biomarkers among the four groups were compared using the posthoc Bonferroni-corrected Mann-Whitney U test. Additionally, in order to explore the independent factors that are attributed to the AoACS, variables with a $\mathrm{P}<0.1$ in univariate linear regression analysis were selected for multiple linear regression analysis. Significant variables were then selected for further analysis using multivariate Cox proportional hazard models. All analyses were performed using JMP for Windows (version 11). A p-value of $<0.05$ was considered statistically significant.

\section{Results}

Baseline Characteristics of the Study Population

The mean age of the enrolled patients was $66.1 \pm 12.9$ years and female patients accounted for $34.7 \%$ of all subjects. The mean duration of dialysis therapy was $63.7 \pm 74.4$ months. 


\section{Kidney Blood Pressure Research}

Table 1. Baseline characteristics of the study subjects according to AoAC severity. AoAC, aortic arch calcification; BMI, body mass index; CVD, cardiovascular disease; PTH, parathyroid hormone; HDL, highdensity lipoprotein; FGF-23, fibroblast growth factor-23

\begin{tabular}{|c|c|c|c|c|c|}
\hline Parameter & $\begin{array}{l}\text { Total }(0-12) \\
(\mathrm{n}=389)\end{array}$ & $\begin{array}{c}\text { Group I (0) } \\
(\mathrm{n}=173)\end{array}$ & $\begin{array}{l}\text { Group II (1-3) } \\
\quad(\mathrm{n}=115)\end{array}$ & $\begin{array}{c}\text { Group III (4-12) } \\
(\mathrm{n}=101)\end{array}$ & $P$ value \\
\hline AoAC score & $2(0-4)$ & $0(0-0)$ & $2(2-3)$ & $5(4-7)$ & $<0.0001$ \\
\hline Age (years) & $66.1 \pm 12.9$ & $60.7 \pm 14.0$ & $69.4 \pm 9.8$ & $71.8 \pm 10.4$ & $<0.0001$ \\
\hline Gender, female (\%) & $135(34.7)$ & $40(23.1)$ & $47(40.9)$ & $48(47.5)$ & $<0.0001$ \\
\hline BMI $\left(\mathrm{kg} / \mathrm{m}^{2}\right)$ & $22.2 \pm 3.7$ & $22.7 \pm 3.7$ & $21.8 \pm 3.4$ & $21.9 \pm 3.9$ & 0.0539 \\
\hline Dialysis vintage (months) & $63.7 \pm 74.4$ & $55.3 \pm 72.9$ & $65.3 \pm 73.4$ & $76.1 \pm 76.7$ & 0.0795 \\
\hline $\mathrm{Kt} / \mathrm{V}$ & $1.37 \pm 0.28$ & $1.33 \pm 0.27$ & $1.38 \pm 0.28$ & $1.41 \pm 0.27$ & 0.0412 \\
\hline Diabetes (\%) & $178(45.8)$ & $68(39.3)$ & $61(53.0)$ & $49(48.5)$ & 0.0587 \\
\hline Hypertension (\%) & $275(72.4)$ & $122(72.6)$ & $77(68.1)$ & $76(76.8)$ & 0.3729 \\
\hline History of CVD (\%) & $39(10.0)$ & $15(8.7)$ & $9(7.8)$ & 15 (14.9) & 0.1673 \\
\hline nPCR & $0.87 \pm 0.19$ & $0.87 \pm 0.17$ & $0.88 \pm 0.22$ & $0.87 \pm 0.19$ & 0.9208 \\
\hline Calcium (Ca, mg/dl) & $8.7 \pm 0.7$ & $8.7 \pm 0.8$ & $8.7 \pm 0.7$ & $8.6 \pm 0.6$ & 0.5897 \\
\hline Phosphate $(\mathrm{P}, \mathrm{mg} / \mathrm{dl})$ & $5.3 \pm 1.5$ & $5.4 \pm 1.6$ & $5.1 \pm 1.4$ & $5.1 \pm 1.4$ & 0.1377 \\
\hline $\mathrm{Ca} \times \mathrm{P}$ products $\left(\mathrm{mg}^{2} / \mathrm{dl}^{2}\right)$ & $45.5 \pm 13.1$ & $47.0 \pm 14.2$ & $44.8 \pm 12.5$ & $43.9 \pm 11.8$ & 0.1309 \\
\hline Hemoglobin $(\mathrm{g} / \mathrm{dl})$ & $10.9 \pm 1.1$ & $11.0 \pm 1.1$ & $10.8 \pm 1.3$ & $10.7 \pm 1.1$ & 0.0604 \\
\hline Intact PTH $(\mathrm{pg} / \mathrm{ml})$ & $109(60-197)$ & $124(64-219)$ & $96(42-162)$ & $114.5(70-182)$ & 0.0248 \\
\hline Albumin (mg/dl) & $3.8 \pm 0.3$ & $3.8 \pm 0.3$ & $3.7 \pm 0.3$ & $3.7 \pm 0.3$ & 0.0187 \\
\hline Alkaline Phosphatase $(\mathrm{mg} / \mathrm{dl})$ & $245.4 \pm 109.2$ & $243.7 \pm 127.6$ & $245.3 \pm 94.5$ & $248.5 \pm 90.1$ & 0.9405 \\
\hline C-reactive protein $(\mathrm{mg} / \mathrm{dl})$ & $0.43 \pm 1.09$ & $0.44 \pm 1.00$ & $0.37 \pm 0.68$ & $0.50 \pm 1.53$ & 0.6632 \\
\hline Total cholesterol (mg/dl) & $158.0 \pm 32.2$ & $158.1 \pm 31.6$ & $154.6 \pm 35.6$ & $161.8 \pm 29.0$ & 0.2646 \\
\hline HDL-cholesterol (mg/dl) & $47.7 \pm 14.0$ & $47.2 \pm 14.4$ & $47.5 \pm 13.6$ & $49.0 \pm 13.7$ & 0.5694 \\
\hline Triglyceride (mg/dl) & $112.3 \pm 68.9$ & $122.2 \pm 75.0$ & $103.2 \pm 67.9$ & $105.6 \pm 56.4$ & 0.0376 \\
\hline Sclerostin $(\mathrm{pg} / \mathrm{ml})$ & $234.2 \pm 132.7$ & $240.2 \pm 139.7$ & $238.8 \pm 130.9$ & $218.7 \pm 121.8$ & 0.3931 \\
\hline FGF-23 (pg/ml) & $4384(1058-12595)$ & $5393(1067-14800)$ & 3453 (833-12100) & 3619 (1218-9499) & 0.2597 \\
\hline Vitamin D & $19(4.9)$ & $7(4.1)$ & $6(5.2)$ & $6(5.9)$ & 0.7666 \\
\hline $\mathrm{CaCO} 3$ & $265(68.1)$ & $119(68.8)$ & $78(67.8)$ & $68(67.39$ & 0.9660 \\
\hline Phosphate binder (Non-Ca) & $187(48.1)$ & $84(48.6)$ & $55(47.8)$ & $48(47.5)$ & 0.9846 \\
\hline
\end{tabular}

Hypertension and diabetes were noted in $72.4 \%$ and $45.8 \%$ of the study population, respectively. One hundred seventy-three subjects $(44.5 \%)$ did not show evidence of AoAC.

\section{Comparison of AoAC severity among groups}

The results of the comparison of the different AoAC severity among patients are summarized in Table 1. Patients without calcification were younger in addition to being less likely to be male, while groups with severe calcification had higher values of Kt/V, intact PTH and triglyceride, and lower albumin values. There were no significant differences in serum levels of calcium, phosphate and calcium phosphate products between the different groups. Furthermore, there was also no significant difference in bone-derived biomarkers such as sclerostin and FGF-23 and prescription of vitamin $\mathrm{D}$ and

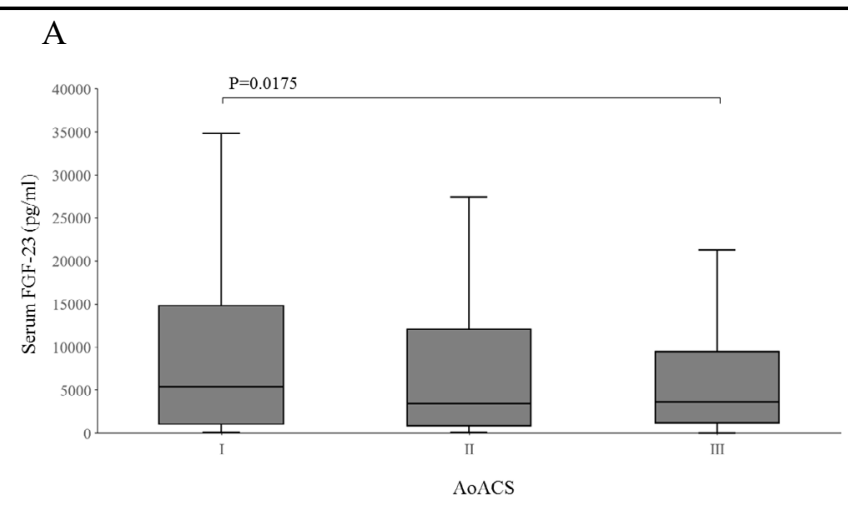

B

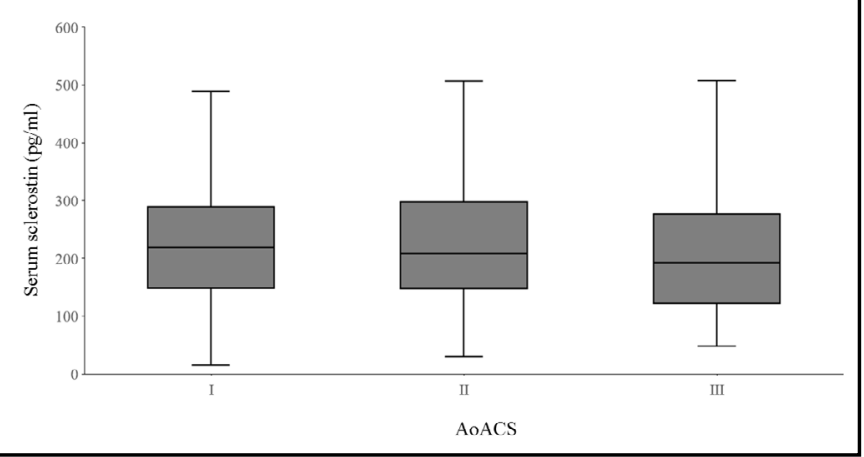

Fig. 1. The relationship between serum levels of FGF23 (a) and sclerostin (b) and the severity of aortic arch calcification score (AoAC). I: AoACS = 0, I: AoACS = 1-3\%; III: 4-12\%. 


\section{Kidney Bloód Pressure Research}

Fig. 2. The relationship between serum FGF23 and sclerostin levels.

phosphate binders between the different groups. After adjusting for the other factors, there was significant difference in serum FGF-23 levels between the different groups (Fig. 1a), but not in serum sclerostin levels (Fig. 1b). Interestingly, we found a decreasing trend in the serum FGF-23 levels with increasing AoAC severity. The BMI values, dialysis vintage, prevalence of diabetes, serum levels of calcium, phosphorous, alkaline phosphatase, and CRP were similar between the four groups.

\section{Relationship between bone-derived} biomarkers and $A o A C$

As shown in Fig. 2, no significant relationship was observed between serum sclerostin and FGF-23 levels. With regard to other bone mineral metabolism parameters, serum sclerostin levels were positively associated with serum phosphorous $(\mathrm{r}=0.115 ; \mathrm{P}=0.00324)$, calcium x phosphate products $(\mathrm{r}=0.126$; $P=0.0188$ ), and negatively associated with serum iPTH levels $(\mathrm{r}=-0.210$; $\mathrm{P}<$ $0.0001)$ ). The serum FGF-23 levels had positive associations with calcium $(\mathrm{r}=$ $0.285, \mathrm{P}<0.0001)$, phosphorous $(\mathrm{r}=$ $0.382, \mathrm{P}<0.0001$ ), calcium $\mathrm{x}$ phosphate products $(\mathrm{r}=0.461, \mathrm{P}<0.0001)$, and iPTH ( $\mathrm{r}=0.117, \mathrm{P}=0.0297$ ). There was a significant relationship between the serum levels of sclerostin and FGF-23 and prescription of phosphate binders. The serum FGF-23 levels (Fig. 3a), but not sclerostin levels (Fig. 3b), were negatively correlated AoACS.

Linear regression analysis of determinants of AoCC

Table 2 shows the results of univariate and multivariate linear regression analysis of the AoACS. Age, gender, and dialysis vintage were independent predictors of AoACS. Unfortunately, serum
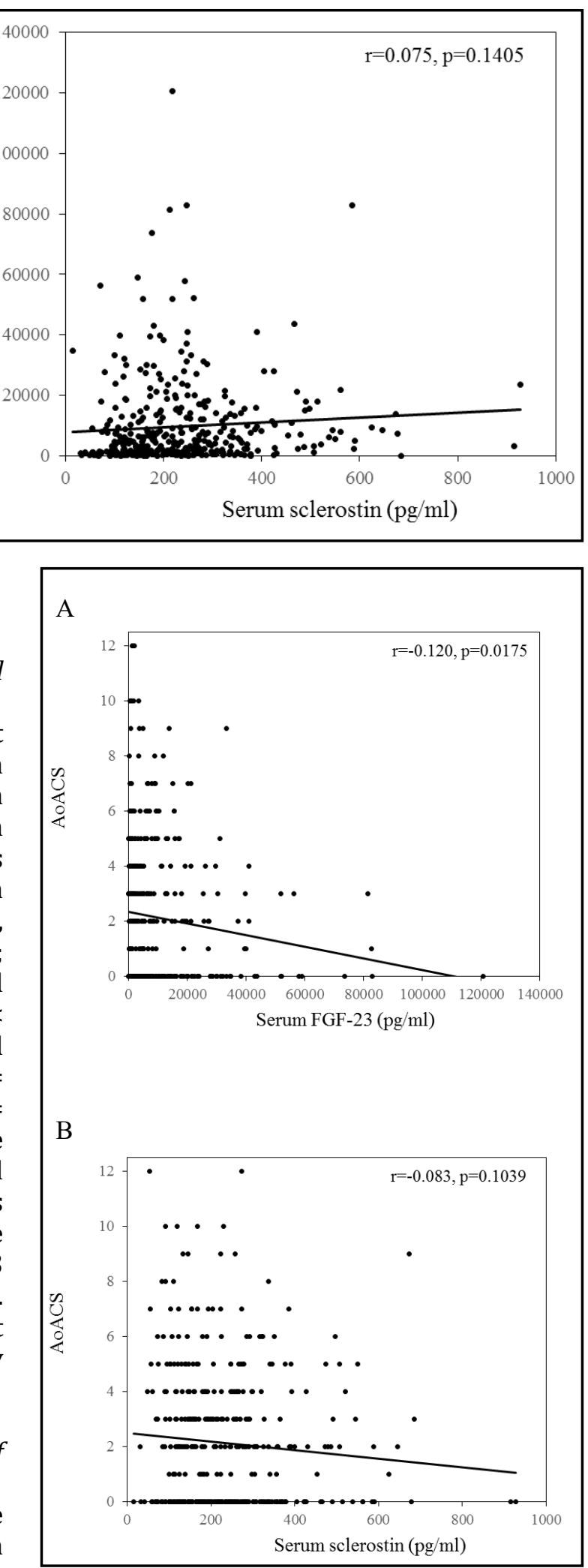

Fig. 3. The relationship between aortic arch calcification score (AoACS) and serum levels of FGF23 (a) and sclerostin (b). 


\section{Kidney Blood Pressure Research}

sclerostin and FGF23 levels were not independent predictors of AoACS.

\section{Discussion}

The results
of this study revealed a high prevalence of AoAC in MHD patients, nearly $50 \%$ of whom, presented with advanced c a l c if ic ation. Furthermore, we found a decreasing trend in the serum FGF-23 as a bonederived biomarker with increasing
Table 2. Clinical factors associated with AoAC score in MHD patients. MHD, maintenance hemodialysis; BMI, body mass index; CVD, cardiovascular disease; PTH, parathyroid hormone; HDL, high-density lipoprotein; FGF-23, fibroblast growth factor-23

\begin{tabular}{lcccccc}
\hline Parameter & $\beta$ & 95\%CI & P value & $\beta$ & 95\%CI & P value \\
\hline Age & 0.345 & 0.251 to 0.439 & $<0.0001$ & 0.347 & 0.237 to 0.458 & $<0.0001$ \\
Gender, female & 0.221 & 0.124 to 0.319 & $<0.0001$ & 0.137 & 0.021 to 0.254 & 0.0206 \\
BMI & -0.097 & -0.185 to -0.009 & 0.0314 & -0.004 & -0.096 to 0.088 & 0.9309 \\
Dialysis vintage & 0.099 & -0.000 to 0.199 & 0.0508 & 0.146 & 0.044 to 0.248 & 0.0053 \\
Kt/V & 0.144 & 0.045 to 0.243 & 0.0044 & -0.032 & -0.156 to 0.091 & 0.6078 \\
Diabetes & 0.057 & -0.043 to 0.156 & 0.2653 & & & \\
Hypertension & 0.030 & -0.068 to 0.128 & 0.5523 & & & \\
History of CVD & 0.070 & -0.030 to 0.170 & 0.1682 & & & \\
nPCR & -0.047 & -0.120 to 0.027 & 0.2121 & & & \\
Calcium (Ca) & -0.018 & -0.118 to 0.082 & 0.7202 & & & \\
Phosphate (P) & -0.080 & -0.180 to 0.019 & 0.1136 & & & \\
Ca $\times$ P products & -0.092 & -0.192 to 0.007 & 0.0693 & 0.035 & -0.073 to 0.144 & 0.5241 \\
Hemoglobin & -0.099 & -0.189 to -0.009 & 0.0303 & -0.064 & -0.149 to 0.020 & 0.1350 \\
Intact PTH & -0.064 & -0.165 to 0.036 & 0.2068 & & & \\
Albumin & -0.120 & -0.219 to -0.020 & 0.0184 & 0.024 & -0.078 to 0.126 & 0.6433 \\
Alkaline Phosphatase & 0.026 & -0.074 to 0.126 & 0.6076 & & & \\
C-reactive protein & 0.035 & -0.065 to 0.135 & 0.4922 & & & \\
Total cholesterol & 0.066 & -0.026 to 0.158 & 0.1575 & & & \\
HDL-cholesterol & 0.046 & -0.050 to 0.142 & 0.3498 & & & \\
Triglyceride & -0.080 & -0.180 to 0.019 & 0.1131 & & & \\
Sclerostin & -0.083 & -0.182 to 0.017 & 0.1039 & -0.041 & -0.141 to 0.060 & 0.4291 \\
FGF-23 & -0.120 & -0.220 to -0.021 & 0.0175 & -0.025 & -0.131 to 0.082 & 0.6488 \\
Vitamin D & 0.011 & -0.089 to 0.111 & 0.8231 & & & \\
CaCO & -0.050 & -0.150 to 0.049 & 0.3214 & & & \\
Phosphate binder (Non-Ca) & 0.009 & -0.091 to 0.109 & 0.8565 & & & \\
\hline & & & & & &
\end{tabular}

AoAC severity. However, serum sclerostin and FGF-23 levels were not independent predictors for the severity of AoAC. Time on dialysis was another factor related to the grade of AoAC.

The classical vascular risk factors which showed independent association with the presence of vascular calcifications were age, dyslipidemia and diabetes, while age was the most significant factor [2]. With respect to dyslipidemia and diabetes, there was no significant association with AoAC in the multivariate model. Ajiro et al. [19] previously reported that older age in association with longer dialysis vintage was an independent mortality risk factor. With age, increased arterial stiffness associated with vascular calcification results in a selective elevation of pulse pressure caused by an increased systolic BP and a decrease of diastolic BP.

Vascular calcification has been considered a risk factor of cardiovascular mortality in ESRD patients. Arterial calcification increase stiffness and reduce elasticity of large arteries such as the aorta, which may result in substantial mortality and morbidity by impairing cardiovascular hemodynamics and vascular compliance [20]. The KDIGO clinical practice guideline recommends plain X-ray films of the lumbar spine for the detection and assessment of cardiovascular calcification in HD patients [21]. The AoAC identified in plain chest X-ray is associated with an increased risk of coronary artery disease and is linked to cardiovascular risk factors such as age, hypertension, dyslipidemia and diabetes mellitus in the general population [22, 23]. Moreover, compared with traditional risk factors, AoAC is an independent determinant of cardiovascular outcome [24]. However, the mechanism of AoAC progression remains unknown and requiring future investigations.

Vascular calcification is a dynamic process that results from an imbalance between promoters and inhibitors [25]. FGF-23 and Klotho have recently been recognized as contributors to ectopic calcification in soft tissues, including cardiac valves and the aorta $[26,27]$. Irrespective of phosphorous levels, FGF-23 independently predicts survival chances of chronic HD patients $[28,29]$. However, whether FGF-23 plays an active pathogenetic role in uremic vascular calcification remains uncertain, and experimental studies have exhibited opposing effects on the calcification process [30,31]. 


\section{Kidney Blood Pressure Research}

Recently, there is growing evidence of the role of the Wnt- $ß$-catenin signaling pathway in vascular calcification. Martinez-Moreno et al. reported that activation of the Wnt/ $\beta$-catenin signaling pathway enhances the phenotype switch and transformation of the vascular smooth cell into the osteoblast-like cell [32]. Moreover, sclerostin has been considered to be as an inhibitor of bone mineralization by suppressing Wnt signaling [33]. However, the relationship between sclerostin and vascular calcification is controversial when considering ESRD patients. Delanaye et al. found no association between sclerostin and the aortic calcification grade in HD patients [34], whereas Pelletier el al. reported that sclerostin levels correlated with aortic calcification severity [35]. Lee et al. have recently revealed a strong association between aortic calcification score and sclerostin, with the level of sclerostin being independently associated with aortic calcification [36]. The results of the present study have shown no association between serum sclerostin and AoAC. The discrepancy might be attributed to the diversity in the study population and detection methods.

The prescription of active vitamin $\mathrm{D}$ and phosphate binders might have an influence on serum sclerostin and FGF-23 levels in MHD patients. Active vitamin D treatment has found to increase serum sclerostin levels in non-dialysis patients with chronic kidney disease (CKD) and such an effect is abolished by the adjustment of PTH, suggesting that it may serve to counter PTH suppression [37]. However, the percentage of active vitamin D and phosphate binder administration was not significantly different among the subjects divided by AoAC severity. Moreover, multivariate analyses showed that serum sclerostin and the prescription of active vitamin $\mathrm{D}$ and phosphate binders were not independent predictors for AoAC. Thus, the prescription of active vitamin $\mathrm{D}$ and phosphate binders are considered not to be major determinants of AoAC in MHD patients.

There are several limitations in the present study. First, the evaluation of AoAC is the semi-quantitative method, thus this method using four grades to evaluate AoAC is relatively crude. Therefore, the true calcium deposition in the aortic wall may be underestimated. However, our previous study confirmed that AoACS was highly correlated with aortic arch calcification volume evaluated by multi-slice CT [9]. Second, the interpretation of the data from our study is limited by the study design. Caution is necessary since this cross-sectional study only accounted for the associations between the biomarkers and vascular calcification, and did not examine the causal relationship between these factors. Third, it is still unknown whether AoAC grade is a sensitive predictor of cardiovascular and all-cause mortality. Finally, we describes a decreasing trend in serum FGF-23 levels with increasing AoAC. This result is conflicting with the majority of clinical studies reported in current literature. Usually, higher levels of FGF-23 are related to severity of vascular damage. We suspect a protective effect of FGF-23 on AoAC. Thus, incident longitudinal prospective studies are needed in order to determine whether sclerostin and FGF-23 truly contribute to calcification genesis and are implicated in clinical outcomes.

\section{Conclusion}

The results of the present study demonstrated the high prevalence of AoAC in MHD patients. The grade of AoAC was dependent on older age in association with longer dialysis vintage. Levels of circulating FGF-23 but not sclerostin levels were associated with the AoAC severity. Serum sclerostin and FGF-23 levels were not predictors for AoAC in these patients.

\section{Acknowledgements}

The authors thank Mr. Toshiaki Naganuma and Mr. Tomonori Kimura for their skillful technical assistance. 


\section{Kidney \\ Blood Pressure Research}

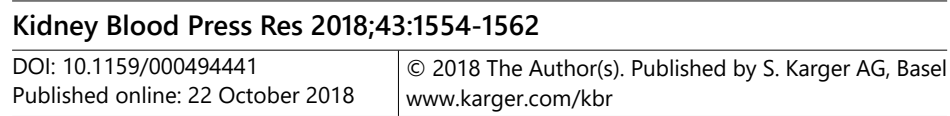

Nitta et al.: Aortic Arch Calcification and Bone-Derived Biomarkers

\section{Disclosure Statement}

The authors have no conflict of interest to disclose.

\section{References}

1 Chirakarnjanakorn S, Navaneethan SD, Francis GS, Tang WH: Cardiovascular impact in patients undergoing maintenance hemodialysis: Clinical management considerations. Int J Cardiol 2017;232:12-23.

-2 Nitta K, Ogawa T: Vascular calcification in end-stage renal disease patients. Contrib Nephrol 2015;185:156167.

3 Cannata-Andia JB, Rodriguez-Garcia M, Carrillo-Lopez N, Naves-Diaz M, Diaz-Lopez B: Vascular calcifications: pathogenesis, management, and impact on clinical outcomes. J Am Soc Nephrol 2006;17:S267-S273.

4 Shanahan CM, Crouthamel MH, Kapustin A, Giachelli CM: Arterial calcification in chronic kidney disease: key roles for calcium and phosphate. Circ Res 2011;109:697-711.

-5 Noordzij M, Cranenburg EM, Engelsman LF, Hermans MM, Boeschoten EW, Brandenburg VM, Bos WJ, Kooman JP, Dekker FW, Ketteler M, Schurgers LJ, Krediet RT, Korevaar JC, NECOSAD Study Group: Progression of aortic calcification is associated with disorders of mineral metabolism and mortality in chronic dialysis patients. Nephrol Dial Transplant 2011;26:1662-1669.

6 Agatston AS, Janowitz WR, Hildner FJ, Zusmer NR, Viamonte M Jr, Detrano R: Quantification of coronary artery calcium using ultrafast computed tomography. J Am Coll Cardiol 1990;15:827-832.

7 Moe SM, O’Neil KD, Fineberg N, Persohn S, Ahmed S, Garret P, Meyer CA: Assessment of vascular calcification in ESRD patients using spiral CT. Nephrol Dial Transplant 2003;18:1152-1158.

8 Iribarren C, Sidney S, Sternfeld B, Browner WS: Calcification of the aortic arch: risk factors and association with coronary heart disease, stroke, and peripheral vascular disease. JAMA 2000;283:2810-2815.

-9 Ogawa T, Ishida H, Matsuda N, Fujiu A, Matsuda A, Ito K, Ando Y, Nitta K: Simple evaluation of aortic arch calcification by chest radiography in hemodialysis patients. Hemodial Int 2009;13:301-306.

-10 Inoue T, Ogawa T, Ishida H, Ando Y, Nitta K: Aortic arch calcification evaluated on chest X-ray is a strong independent predictor of cardiovascular events in chronic hemodialysis patients. Heart Vessels 2012;27:135-142.

11 Asamiya Y, Ken Tsuchiya, Nitta K: Role of sclerostin in the pathogenesis of chronic kidney disease-mineral bone disorder. Ren Replace Ther 2016;2:8.

12 Cejka D, Herberth J, Branscum AJ, Fardo DW, Monier-Faugere MC, Diarra D, Haas M, Malluche HH: Sclerostin and Dickkopf-1 in renal osteodystrophy. Clin J Am Soc Nephrol 2011;6:877-882.

13 Sabbagh Y, Graciolli FG, O’Brien S, Tang W, dos Reis LM, Ryan S, Phillips L, Boulanger J, Song W, Bracken C, Liu S, Ledbetter S, Dechow P, Canziani ME, Carvalho AB, Jorgetti V, Moyses RM, Schiavi SC: Repression of osteocyte Wnt/beta-catenin signaling is an early event in the progression of renal osteodystrophy. J Bone Miner Res 2012;27:1757-1772.

14 Viaene L, Behets GJ, Claes K, Meijers B, Blocki F, Brandenburg V, Evenepoel P, D’Haese PC: Sclerostin: another bone-related protein related to all-cause mortality in haemodialysis? Nephrol Dial Transplant 2013;28:3024-3030.

15 Heiland GR, Zwerina K, Baum W, Kireva T, Distler JH, Grisanti M, Asuncion F, Li X, Ominsky M, Richards W, Schett G, Zwerina J: Neutralisation of Dkk-1 protects from systemic bone loss during inflammation and reduces sclerostin expression. Ann Rheum Dis 2010;69:2152-2159.

16 Tamei N, Ogawa T, Ishida H, Ando Y, Nitta K: Serum fibroblast growth factor-23 levels and progression of aortic calcification in non-diabetic patients on chronic hemodialysis. J Atheroscler Thromb 2011;18:217223.

17 Sugimoto H, Ogawa T, Iwabuchi Y, Otsuka K, Nitta K: Relationship between serum fibroblast growth factor-23 level and mortality in chronic hemodialysis patients. Int Urol Nephrol 2014;46:99-106.

18 Asamiya Y, Yajima A, Shimizu S, Otsubo S, Tsuchiya K, Nitta K: Associations between the levels of sclerostin, phosphate, and fibroblast growth factor-23 and treatment with vitamin D in hemodialysis patients with low intact PTH level. Osteoporos Int 2015;26:1017-1028. 


\section{Kidney \\ Blood Pressure Research}

19 Ajiro J, Alchi B, Narita I, Omori K, Kondo D, Sakatsume M, Kazama JJ, Akazawa K, Gejyo F: Mortality predictors after 10 years of dialysis: A prospective study of Japanese hemodialysis patients. Clin J Am Soc Nephrol 2007;2:653-660.

20 London GM, Guerin AP, Marchais SJ, Metivier F, Pannier B, Adda H: Arterial media calcification in end-stage renal disease: impact on all-cause and cardiovascular mortality. Nephrol Dial Transplant 2003;18:17311740.

-21 Kidney Disease: Improving Global Outcomes (KDIGO) CKD-MBD Work Group: KDIGO clinical practice guideline for the diagnosis, evaluation, prevention, and treatment of Chronic Kidney Disease-Mineral and Bone Disorder (CKD-MBD). Kidney Int Suppl 2009:S1-S130.

22 Symeonidis G, Papanas N, Giannakis I, Mavridis G, Lakasas G, Kyriakidis G, Artopoulos I: Gravity of aortic arch calcification as evaluated in adult Greek patients. Int Angiol 2002;21:233-236.

23 Li J, Galvin HK, Johnson SC, Langston CS, Sclamberg J, Preston CA: Aortic calcification on plain chest radiography increases risk for coronary artery disease. Chest 2002;121:1468-1471.

24 Iijima K, Hashimoto H, Hashimoto M, Son BK, Ota H, Ogawa S, Eto M, Akishita M, Ouchi Y: Aortic arch calcification detectable on chest X-ray is a strong independent predictor of cardiovascular events beyond traditional risk factors. Atherosclerosis 2010;210:137-144.

-25 Nitta K: Vascular calcification in patients with chronic kidney disease. Ther Apher Dial 2011;15:513-521.

-26 Nakatani T, Sarraj B Ohnishi M, Densmore MJ, Taguchi T, Goetz R, Mohammadi M, Lanske B, Razzaque MS: In vivo genetic evidence for kloth-dependent, fibroblast growth factor 23 (Fgf23)-mediated regulation of systemi phosphate homeostasis. FASEB J 2009;23:433-441.

27 Hu MC, Shi M, Zhang J, Quinones H, Griffith C, Huro-o M, Moe OW. Klotho deficiency causes vascular calcification in chronic kidney disease. J Am Soc Nephrol 2011;22:124-136.

-28 Gutiérrez OM, Mannstadt M, Isakova T, Rauth-Hain JA, Tamez H, Shan A, Smith K, Lee H, Thahani R, Juppner $\mathrm{H}$, Wolf M: Fibroblast growth factor 23 and mortality among patients undergoing hemodialysis, N Engl J Med 2008;359:584-592.

-29 Jean G, Terrat JC, Vanel T, Hurot JM, Lorriaux C, Mayor B, Chazot C: High levels of serum fibroblast growth factor (FGF)-23 are associated with increased mortality in long haemodialysis patients, Nephrol Dial Transplant 2009;24:2792-2796.

-30 Zhu D, Mackenzie NC, Millan JL, Farquharson C, MacRae VE: A protective role for FGF-23 in local defence against disrupted arterial wall integrity? Mol Cell Endocrinol 2013;372:1-11.

31 Jimbo R, Kawakami-Mori F, Mu S, Hirohama D, Majtan B, Shimizu Y, Yatomi Y, Fukumoto S, Fujita T, Shimosawa T: Fibroblast growth factor 23 accelerates phosphate-induced vascular calcification in the absence of Klotho deficiency, Kidney Int 2014;85:1103-1111.

-32 Martínez-Moreno JM, Muñoz-Castañeda JR, Herencia C, Oca AM, Estepa JC, Canalejo R, Rodríguez-Ortiz ME, Perez-Martinez P, Aguilera-Tejero E, Canalejo A, Rodortguez M, Almaden Y: In vascular smooth muscle cells paricalcitol prevents phosphate-induced Wnt/ $\beta$-catenin activation, Am J Physiol Ren Physiol 2012;303:F1136-F1144.

-33 Ott SM: Bone cells, sclerostin, and FGF23: what's bred in the bone will come out in the flesh. Kidney Int 2015;87:499-501.

-34 Delanaye P, Krzesinski JM, Warling X, Moonen M, Smelten N, Medart L, Bruyere O, Reginster JY, Pottel $\mathrm{H}$, Cavalier E: Clinical and biological determinants of sclerostin plasma concentration in hemodialysis patients, Nephron Clin Pract 2014;128:127-134.

-35 Pelletier S, Confavreux CB, Haesebaert J, Guebre-Egziabher F, Bacchetta J, Cartier MC, Chardon L, Laville M, Chapurlat R, London GM, Lafage-Proust MH, Fouque D: Serum sclerostin: the missing link in the bonevessel cross-talk in hemodialysis patients? Osteoporos Int 2015;26:2165-2174.

-36 Lee YT, Ng HY, Chiu TTY, Li LC, Pei SN: Association of bone-derived biomarkers with vascular calcification in chronic hemodialysis patients. Clin Chim Acta 2016;452:38-43.

37 Torino C, Pizzini P, Cutrupi S, Tripepi G, Mallamaci F, Thadhani R, Zoccali C: Active vitamin D treatment in CKD patients raises serum sclerostin and its effect is modified by circulating pentosidine levels. Nutr Metab Cardiovasc Dis 2017;27:260-266. 